\title{
Impact of COVID-19 Pandemic and National Lockdown on Mental Health among General Urban Indian Population: An Online based Cross-Sectional Survey
}

\author{
Jyoti Sharma ${ }^{1}$, Irshad Ahmad ${ }^{2}$, Shahin Naz Jamali ${ }^{3}$, Yamini Sharma ${ }^{1}$, \\ Megha Yadav $^{1}$, Sakhshi Arora ${ }^{1}$, Mangalam Kumari ${ }^{1}$ \\ ${ }^{I}$ Assistant Professor, School of Medical and Allied Sciences, Galgotias University, Greater Noida, Uttar Pradesh, \\ ${ }^{2}$ Assistant Professor, Faculty of Allied Health Sciences, Manav Rachna International Institute of Research and \\ Studies, Faridabad, Haryana, ${ }^{3}$ Assistant Professor, School of Health Sciences, Noida International University, \\ Greater Noida, Uttar Pradesh
}

\begin{abstract}
Purpose: The aim of the study is to assess the prevalence of anxiety and depression among the urban Indian population during the period of national lockdown imposed by the government of India to combat the COVID-19 pandemic

Method: Total 278 participants were participated in an online, cross-sectional survey. Anxiety and depression was assessed. Gender, age, occupation and average time spent on gathering information on COVID-19 was assessed.

Results: less than 30 years of age and students showed higher prevalence of depression. Participants spending more than three hours on COVID-19 information showed that $18.2 \%, 42.4 \%$ and $37.9 \%$ were mildly, moderately and severely affected by anxiety symptoms, respectively and $19.7 \%, 47 \%$ and $24.2 \%$ were mildly, moderately and severely affected with depression. Further, more than three hours of time spent on COVID-19 showed strong association with mild, moderate and severe anxiety $(\mathrm{p}<0.001)$ as well as mild, moderate and severe depression $(\mathrm{p} \leq 0.01)$.

Conclusions: Participants, less than 30 years of age and students were found more likely to have anxiety and depression symptoms. Participants who have been spending more than three hours on COVID-19 information were strongly affected with mild, moderate and severe anxiety as well as depression.
\end{abstract}

Keywords: Anxiety, Depression, GAD-7, PHQ-9, Psychological Illness, Mental Illness.

\section{Introduction}

World health organization (WHO) declared the novel coronavirus disease 2019 (COVID-19) a health emergency in January 2020 and declared it a pandemic

\section{Corresponding Author:}

Irshad Ahmad

Assistant Professor, Faculty of Allied Health Sciences, Manav Rachna International Institute of Research and Studies, Faridabad, Haryana

e-mail: irshad.ahmadjmi10@gmail.com in March 2020. On 02 ${ }^{\text {nd }}$ April 2020, the total number of confirmed cases of COVID-19 were estimated at 938,348 with 48,571 deaths around the world due to the disease $^{(1)}$. In India, the first confirmed case of COVID-19 was reported on 30 January 2020. The number of confirmed cases increased to 1027 by 29 February 2020 which further increased to 2192 confirmed cases by 02 April 2020 and the count is rapidly increasing ${ }^{(2)}$.

Previous study has reported on mental health crisis in China due to COVID-19, and said a health emergency occurring due to an epidemic of an infectious disease can prompt unfavorable situations and lead to long 
lasting psychological consequences ${ }^{(3)}$. Any epidemic or outbreak of infectious disease can have a wide range of psychiatric comorbidities like stress, panicattacks, fear, depression and anxiety ${ }^{(4-6)}$. In addition, quarantine has been associated with high stress levels, depression, irritability and insomnia ${ }^{(7,8)}$. An investigation concerning COVID-19 pandemic reported a rate of 20.8-34\% anxiety and $17.3-18.1 \%$ depression among general population ${ }^{(10-12)}$. In India, a study conducted on the effect of pandemic of COVID-19 and resultant lockdown also suggestsa significant adverse effect on the mental status of the population ${ }^{(12)}$.

Therefore, the aim of the present study is to explore the prevalence and potential factors associated with anxiety and depression during the initial 21 days of national lockdown, imposed due to the spread of COVID-19 pandemic, among the urban Indian population.

\section{Materials and Method}

Study Design and Participants: A crosssectional survey was conducted to assess the immediate psychological response of anxiety and depression during the epidemic of COVID-19 by using snowball sampling. Ethical approval was obtained and the study was conducted in accordance with the Helsinki Declaration.

Out of total 294 respondents, response of 278 participants were included on the basis of inclusion and exclusion criteria. Inclusion criteria were Indian participants, both gender,above 18 years of age and able to understand the English language. Health-care workers, sanitation workers, security professionals and delivery professionals were excluded. An online consent was taken from each participant before they answered the questionnaire. The participation was completely voluntary and non-commercial.

Procedure: An online survey was done using the questionnaire developed through 'Google forms' with attached consent form. The web link was circulated through e-mails and social networking mediums. Participants were encouraged to circulate the survey. On clicking the web link, participants were auto directed to a page containing demographic information, average time spend on gathering information on COVID-19, followed by the Generalized Anxiety Disorder (GAD-7) questionnaire and Patient Health Questionnaire (PHQ9). Data collection, initiated on $29^{\text {th }}$ march 2020 and culminated on $2^{\text {nd }}$ April 2020, that is, during the initial phase of national lockdown.

Demographic Characteristics: The variables of demographic data included gender (male and female), age $(<30$ years and $\geq 30$ years $)$, and occupation which was categorized into (a) public sector employees, (b) private sector employees,(c) students and (d) others

Average time spent on COVID-19 information everyday: This section questioned the participants on the average time they spent each day on electronic, print, and social media for gathering information on COVID-19. Average time spent to gather information on COVID-19 was divided into three categories: (a) less than one hour ( $<1$ hour), (b) one to three hours(1-3 hours), and (c) more than three hours ( $>3$ hours).

Generalized Anxiety: The GAD-7 questionnaire is a 7-item self-assessment scale developed to assess the defining symptoms of general anxiety disorder ${ }^{(13)}$. Items in the scale were rated on a 4-point Likert scale. According toGAD-7, a score ranging from 0-4, 5-9, 10-14 and 14-21 represents absent, mild, moderate and severe anxiety, respectively ${ }^{(13)}$.

Depression: PHQ-9 is also a self-assessment tool for depression with a 4-point Likert scale. PHQ-9 scores ranging from 0-4, 5-9, 10-19 and 20-27 represent absent, mild, moderate and severe depression symptoms, respectively ${ }^{(14)}$.

Statistical analysis: All statistical analyses were carried out using SPSS version 24. Descriptive statistics were calculated for demographic characteristics including gender, age, occupation and average time spent on COVID-19 information every day. Prevalence of generalized anxiety and depression was stratified according to above characteristics, and chi-square test was used to compare the differences in responses between different groups. Univariate and multivariate logistic regression were performed to explore potential factors associated with generalized anxiety and depression. Statistical significance was indicated if $\mathrm{p} \leq 0.05$ and confidence interval was set at $95 \%$. The scores of the GAD-7 and PHQ-9 were expressed in frequency.

\section{Results}

Absolute and frequency distribution of generalized anxiety and depression has been reported in Table 1 and 2 . 
Prevalence of Generalized Anxiety and Depression Stratified by Gender, Age, Occupation and Time Spent Gathering Information on COVID-19 Pandemic: Prevalence of generalized anxiety and depression is illustrated in Table 1 and Table 2, respectively. There was no statistical significant difference in the prevalence of anxiety between males and females, $<30$ years and $\geq 30$ years, or the participants involved in different occupations. However,significant difference was in the prevalence of anxiety between participants who spent $<1$ hour, 1-3 hours and $>3$ hours of average time spent on gathering information on COVID $19(\mathrm{p}<0.001)$ Table 1.

There was no significant difference in the prevalence of depression between males and females. The prevalence of depression was significantly higher $(p=0.015)$ in participants of $<30$ years than $\geq 30$ years of age (Table 2 ). There was significant difference found in the prevalence of depression between participants belonging to different occupations groups $(p=0.01)$. Students showed higher prevalence of depression than public and private sector employees (Table 2). Similarly, significant difference was found in the prevalence of depression between different time spent on COVID-19 $(p<0.001)$. $>3$ hours of time spent showed higher prevalence of depression than 1-3 hours and $<1$ hours of time spent on COVID-19 (Table 2).

Factors Associated with Generalized Anxiety and Depression during COVID-19 Pandemic: Univariate and multivariate logistic regressions revealed that only average time spent on COVID-19 $(p<0.001)$ showed significant association with the severity of generalized anxiety. $>3$ hours of time spent on COVID-19 showed strong association with mild $(\mathrm{p}<0.001)$, moderate $(p<0.001)$ and severe $(p<0.001)$ anxiety (Table 3$)$. Also, multivariate logistic regression analysisshowed the significant association of students $(\mathrm{p}=0.04)$ with only mild anxiety during COVID-19 pandemic (Table3).

The univariate logistic regression analysis showed a significant association of age $(p<0.04)$ and average time spent on COVID-19 $(p<0.001)$ with severity of depression. Participants $<30$ years of age showed strong association with mild $(p=0.008)$, moderate $(p=0.03)$ and severe $(\mathrm{p}=0.04)$ depression (Table 4$)$. Similarly, $>3$ hours of time spent on COVID-19 was found to have strong association with mild $(\mathrm{p}=0.01)$, moderate $(\mathrm{p}<0.001)$ and severe $(\mathrm{p}<0.001)$ depression (Table 4). Additionally, there was significant association of students with moderate depression $(p=0.02)$ even after adjusting other factors $(\mathrm{p}=0.01)$ (Table 4$)$.

Table 1. Prevalence of generalize anxiety (GAD-7) stratified by gender, age, occupation and average time spent on COVID-19 in the participants.

\begin{tabular}{|c|c|c|c|c|c|c|}
\hline \multirow{3}{*}{ Variables } & \multirow{3}{*}{$\begin{array}{c}\begin{array}{c}\text { Anxiety } \\
\text { Absent }\end{array} \\
\mathbf{n}(\%)\end{array}$} & \multicolumn{3}{|c|}{ Anxiety Present } & \multirow{3}{*}{$\chi^{2}$} & \multirow{3}{*}{ p-value } \\
\hline & & Mild & Moderate & Severe & & \\
\hline & & $n(\%)$ & $n(\%)$ & $n(\%)$ & & \\
\hline Total $(\mathrm{N}=278)$ & $139(50.0)$ & $76(27.3)$ & $37(13.3)$ & $26(9.4)$ & & \\
\hline Gender & & & & & 2.86 & 0.413 \\
\hline Male $(\mathrm{N}=122)$ & $67(54.9)$ & $28(23.0)$ & $16(13.1)$ & $11(9.0)$ & & \\
\hline Female $(\mathrm{N}=156)$ & $71(45.5)$ & $48(30.8)$ & $21(13.5)$ & $16(10.3)$ & & \\
\hline Age & & & & & 3.68 & 0.297 \\
\hline$<30$ year $(\mathrm{N}=181)$ & $85(47.0)$ & $50(27.6)$ & $29(16.0)$ & $17(9.4)$ & & \\
\hline$\geq 30$ year $(\mathrm{N}=97)$ & $53(54.6)$ & $26(26.8)$ & $8(8.2)$ & $10(10.3)$ & & \\
\hline Occupation & & & & & 9.14 & 0.429 \\
\hline Public sector $(\mathrm{N}=17)$ & $10(58.8)$ & $5(29.4)$ & $1(5.9)$ & $1(5.9)$ & & \\
\hline Private sector $(\mathrm{N}=73)$ & $38(52.1)$ & $17(23.3)$ & $9(12.3)$ & $9(12.3)$ & & \\
\hline Students $(\mathrm{N}=160)$ & $71(44.4)$ & $48(30.0)$ & $26(16.3)$ & $15(9.4)$ & & \\
\hline Others $(\mathrm{N}=28)$ & $19(67.9)$ & $6(21.4)$ & $1(3.6)$ & $2(7.1)$ & & \\
\hline
\end{tabular}




\begin{tabular}{|c|c|c|c|c|c|c|}
\hline \multirow{3}{*}{ Variables } & \multirow{3}{*}{$\begin{array}{c}\begin{array}{c}\text { Anxiety } \\
\text { Absent }\end{array} \\
\mathbf{n}(\%)\end{array}$} & \multicolumn{3}{|c|}{ Anxiety Present } & \multirow{3}{*}{$\chi^{2}$} & \multirow{3}{*}{ p-value } \\
\hline & & Mild & Moderate & Severe & & \\
\hline & & $n(\%)$ & $n(\%)$ & $n(\%)$ & & \\
\hline \multicolumn{5}{|c|}{ Average Time Spent on COVID-19 } & 173.48 & $<0.001^{*}$ \\
\hline$<1$ hours $(\mathrm{N}=36)$ & $28(77.8)$ & $6(16.7)$ & $1(2.8)$ & $1(2.8)$ & & \\
\hline $1-3$ hours $(N=176)$ & $109(61.9)$ & $58(33)$ & $8(4.5)$ & $1(0.6)$ & & \\
\hline$>3$ hours $(\mathrm{N}=66)$ & $1(1.5)$ & $12(18.2)$ & $28(42.4)$ & $25(37.9)$ & & \\
\hline
\end{tabular}

n: number of participants; \%: percentage; $<30$ years: less than 30 years of age; $\geq 30$ years: more than or equal to 30 years of age; $<1$ hours: less than 1 hour time spent; 1-3 hours: one to three hour of time spent; $>3$ hours: more than three hours of time spent; *: significant difference.

Table 2. Prevalence of depression (PHQ-9) stratified by gender, age,occupation and average time spent on COVID-19 in the participants.

\begin{tabular}{|c|c|c|c|c|c|c|}
\hline \multirow{3}{*}{ Variables } & \multirow{3}{*}{$\begin{array}{c}\begin{array}{c}\text { Depression } \\
\text { Absent }\end{array} \\
\mathbf{n}(\%)\end{array}$} & \multicolumn{3}{|c|}{ Depression Present } & \multirow{3}{*}{$\chi^{2}$} & \multirow{3}{*}{ p-value } \\
\hline & & Mild & Moderate & Severe & & \\
\hline & & n (\%) & n (\%) & n (\%) & & \\
\hline Total $(\mathrm{N}=278)$ & $108(38.8)$ & $75(27.0)$ & $70(25.2)$ & $25(9.0)$ & & \\
\hline Gender & & & & & 3.94 & 0.267 \\
\hline Male $(\mathrm{N}=122)$ & $53(43.4)$ & $35(28.7)$ & $25(20.5)$ & $9(7.4)$ & & \\
\hline Female $(\mathrm{N}=156)$ & $55(35.3)$ & $40(25.6)$ & $45(28.8)$ & $16(10.3)$ & & \\
\hline Age & & & & & 10.46 & $0.015^{*}$ \\
\hline$<30$ year $(\mathrm{N}=181)$ & $58(32.0)$ & $55(30.4)$ & $49(27.1)$ & $19(10.5)$ & & \\
\hline$\geq 30$ year $(\mathrm{N}=97)$ & $50(51.5)$ & $20(20.6)$ & $21(21.6)$ & $6(6.2)$ & & \\
\hline Occupation & & & & & 21.6 & $0.01 *$ \\
\hline Public sector $(\mathrm{N}=17)$ & $11(64.7)$ & $4(23.5)$ & $1(5.9)$ & $1(5.9)$ & & \\
\hline Private sector $(\mathrm{N}=73)$ & $37(50.7)$ & $13(17.8)$ & $17(23.3)$ & $6(8.2)$ & & \\
\hline Students $(\mathrm{N}=160)$ & $45(28.1)$ & $51(31.9)$ & $48(30)$ & $16(10)$ & & \\
\hline Others $(\mathrm{N}=28)$ & $15(53.6)$ & $7(25)$ & $4(14.3)$ & $2(7.1)$ & & \\
\hline \multicolumn{5}{|c|}{ Average Time Spent on COVID-19 } & 60.79 & $<0.001 *$ \\
\hline$<1$ hours $(\mathrm{N}=36)$ & $19(52.8)$ & $9(25.0)$ & $6(16.7)$ & $2(5.6)$ & & \\
\hline $1-3$ hours $(\mathrm{N}=176)$ & $83(47.2)$ & $53(30.1)$ & $33(18.8)$ & $7(4.0)$ & & \\
\hline$>3$ hours $(\mathrm{N}=66)$ & $6(9.1)$ & $13(19.7)$ & $31(47.0)$ & $16(24.2)$ & & \\
\hline
\end{tabular}

n: number of participants; \%: percentage; $<30$ years: less than 30 years of age; $\geq 30$ years: more than or equal to 30 years of age; $<1$ hours: less than 1 hour time spent; 1-3 hours: one to three hour of time spent; $>3$ hours: more than three hours of time spent; *: significant difference.

Table 3. Univariate and multivariate logistic regression analysis of potential factors for severity of generalized anxiety (GAD-7).

\begin{tabular}{|l|c|c|c|c|c|c|}
\hline \multirow{2}{*}{ Variables } & \multicolumn{2}{|c|}{ Mild Anxiety } & \multicolumn{2}{c|}{ Moderate Anxiety } & \multicolumn{2}{c|}{ Severe Anxiety } \\
\cline { 2 - 8 } & OR (95\% CI) & AOR (95\%CI) & OR (95\% CI) & AOR (95\%CI) & OR (95\% CI) & AOR (95\%CI) \\
\hline Gender & $0.61(0.34-1.09)$ & $0.58(0.31-1.08)$ & $0.8(0.38-1.67)$ & $0.85(0.32-2.2)$ & $0.72(0.31-1.68)$ & $0.76(0.24-2.33)$ \\
\hline Male & 1.00 & 1.00 & 1.00 & 1.00 & 1.00 & 1.00 \\
\hline Female & & &
\end{tabular}




\begin{tabular}{|c|c|c|c|c|c|c|}
\hline \multirow{2}{*}{ Variables } & \multicolumn{2}{|c|}{ Mild Anxiety } & \multicolumn{2}{|c|}{ Moderate Anxiety } & \multicolumn{2}{|c|}{ Severe Anxiety } \\
\hline & OR $(95 \%$ CI $)$ & AOR (95\%CI) & OR $(95 \%$ CI) & AOR (95\%CI) & OR $(95 \%$ CI $)$ & AOR (95\%CI) \\
\hline \multicolumn{7}{|l|}{ Age } \\
\hline$<30$ year & $1.19(0.66-2.15)$ & $0.52(0.19-1.39)$ & $2.26(0.96-5.31)$ & $1.02(0.21-4.98)$ & $1.06(0.45-2.48)$ & $0.52(0.08-3.27)$ \\
\hline$\geq 30$ year & 1.00 & 1.00 & 1.00 & 1.00 & 1.00 & 1.00 \\
\hline \multicolumn{7}{|l|}{ Occupation } \\
\hline Public sector & $1.58(0.38-6.5)$ & $2.13(0.48-9.43)$ & $1.9(0.1-33.7)$ & $5.1(0.2-127.64)$ & $0.95(0.07-11.8)$ & $4.72(0.16-132.31)$ \\
\hline Private sector & $1.41(0.48-4.17)$ & $1.87(0.58-5.97)$ & $4.5(0.53-38.17)$ & $5.78(0.46-71.9)$ & $2.25(0.44-11.46)$ & $3.81(0.37-38.78)$ \\
\hline Students & $2.14(0.79-5.75)$ & $\begin{array}{c}4.41(1.01- \\
19.12)^{*}\end{array}$ & $6.95(0.88-54.61)$ & $5.51(0.32-93.72)$ & $2(0.42-9.55$ & $2.66(0.15-45.11)$ \\
\hline Others & 1.00 & 1.00 & 1.00 & 1.00 & 1.00 & 1.00 \\
\hline \multicolumn{7}{|c|}{ Average Time Spent on COVID-19 } \\
\hline$<1$ hours & 1.00 & 1.00 & 1.00 & 1.00 & 1.00 & 1.00 \\
\hline 1-3 hours & $2.48(0.972-6.34)$ & $2.38(0.92-6.17)$ & $2.05(0.24-17.12)$ & $2.06(0.24-17.33)$ & $0.25(0.01-4.23)$ & $0.23(0.01-3.88)$ \\
\hline$>3$ hours & $\begin{array}{c}56(6.06- \\
516.84)^{* *}\end{array}$ & $\begin{array}{c}53.59(5.75- \\
499.5)^{* *}\end{array}$ & $\begin{array}{c}\text { 784(46.69- } \\
13164.49)^{* *}\end{array}$ & $\begin{array}{c}\text { 755.31(44.85- } \\
12720.11)^{* *}\end{array}$ & $\begin{array}{c}700(41.56- \\
11788)^{* *}\end{array}$ & $\begin{array}{c}711.52(41.85- \\
12097.1)^{* *}\end{array}$ \\
\hline
\end{tabular}

n: number of participants; $\%$ : percentage; $<30$ years: less than 30 years of age; $\geq 30$ years: more than or equal to 30 years of age; $<1$ hours: less than 1 hour time spent; $1-3$ hours: one to three hour of time spent; $>3$ hours: more than three hours of time spent; OR: odds ratio; AOR: adjusted odds ratio; $95 \% \mathrm{CI}$ : confidence interval at $95 \%$; : $\mathrm{p}<0.05 ; * *$ : $<<0.01$

Table 4. Univariate and multivariate logistic regression analysis of potential factors for severity of depression (PHQ-9).

\begin{tabular}{|c|c|c|c|c|c|c|}
\hline \multirow{2}{*}{ Variables } & \multicolumn{2}{|c|}{ Mild Depression } & \multicolumn{2}{|c|}{ Moderate Depression } & \multicolumn{2}{|c|}{ Severe Depression } \\
\hline & OR (95\% CI) & $\operatorname{AOR}(95 \% C I)$ & OR $(95 \%$ CI $)$ & $\operatorname{AOR}(95 \% \mathrm{CI})$ & OR $(95 \%$ CI $)$ & $\operatorname{AOR}(95 \% \mathrm{CI})$ \\
\hline \multicolumn{7}{|l|}{ Gender } \\
\hline Male & $0.9(0.5-1.63)$ & $0.97(0.52-1.8)$ & $0.57(0.31-1.06)$ & $0.57(0.29-1.12)$ & $0.58(0.23-1.43)$ & $0.6(0.23-1.59)$ \\
\hline Female & 1.00 & 1.00 & 1.00 & 1.00 & 1.00 & 1.00 \\
\hline \multicolumn{7}{|l|}{ Age } \\
\hline$<30$ year & $\begin{array}{c}2.37(1.25- \\
4.48)^{* *}\end{array}$ & $1.36(0.52-3.58)$ & $2.01(1.06-3.79)^{*}$ & $0.76(0.25-2.24)$ & $2.73(1.01-7.36)^{*}$ & $2.15(0.46-9.94)$ \\
\hline$\geq 30$ year & 1.00 & 1.00 & 1.00 & 1.00 & 1.00 & 1.00 \\
\hline \multicolumn{7}{|l|}{ Occupation } \\
\hline Public sector & $0.77(0.18-3.33)$ & $0.74(0.16-3.28)$ & $0.34(0.03-3.48)$ & $0.45(0.04-4.94)$ & $0.68(0.05-8.5)$ & $0.98(0.06-13.97)$ \\
\hline Private sector & $0.75(0.25-2.25)$ & $0.68(0.21-2.17)$ & $1.72(0.49-5.97)$ & $1.93(0.5-7.37)$ & $1.21(0.22-6.71)$ & $0.86(0.12-5.81)$ \\
\hline Students & $2.42(0.9-6.48)$ & $2.22(0.54-9.14)$ & $4(1.23-12.95)^{*}$ & $\begin{array}{c}8.19(1.48- \\
45.09)^{*}\end{array}$ & $2.66(0.54-12.97)$ & $1.25(0.13-11.57$ \\
\hline Others & 1.00 & 1.00 & 1.00 & 1.00 & 1.00 & 1.00 \\
\hline \multicolumn{7}{|c|}{ Average Time Spent on COVID-19 } \\
\hline$<1$ hours & 1.00 & 1.00 & 1.00 & 1.00 & 1.00 & 1.00 \\
\hline 1-3 hours & $1.34(0.56-3.2)$ & $1.41(0.58-3.43)$ & $1.25(0.46-3.43)$ & $1.23(0.44-3.46)$ & $0.8(0.15-4.16)$ & $0.84(0.16-4.45)$ \\
\hline$>3$ hours & $4.57(1.3-15.97)^{*}$ & $\begin{array}{c}4.48(1.26- \\
15.94)^{*}\end{array}$ & $\begin{array}{c}16.36(4.6- \\
58.11)^{* *}\end{array}$ & $\begin{array}{c}15.82(4.35- \\
57.53)^{* *}\end{array}$ & $\begin{array}{c}25.33(4.47- \\
143.32)^{* *}\end{array}$ & $\begin{array}{c}25.64(4.46- \\
147.32)^{* *}\end{array}$ \\
\hline
\end{tabular}

n: number of participants; \%: percentage; $<30$ years: less than 30 years of age; $\geq 30$ years: more than or equal to 30 years of age; $<1$ hours: less than 1 hour time spent; $1-3$ hours: one to three hour of time spent; $>3$ hours: more than three hours of time spent; OR: odds ratio; AOR: adjusted odds ratio; $95 \% \mathrm{CI}$ : confidence interval at $95 \%$; * $\mathrm{p}<0.05 ; * *$ : $<0.01$ 


\section{Discussion}

Results of present surveyindicated that 50\% participants was affected with anxiety symptoms because of the COVID-19 outbreak and lockdown, out of which $27.3 \%$ have mild, $13.3 \%$ have moderate and $9.4 \%$ have severe symptoms of anxiety. Similarly, $61.2 \%$ participants experienced depression, out of which $27 \%$ reported mild, $25.2 \%$ reported moderate and $9 \%$ reported severe symptoms of depression.

The present study found equal prevalence of anxiety and depression symptoms in male and female. We found similar results as the study conducted in China ${ }^{(10)}$, whereas, the study conducted in Italy and hardest hit areas of China showed that women are more anxious than men due to the COVID-19 pandemic ${ }^{(11,15)}$. An epidemic of any infectious disease leads to an increase in the prevalence of mental illness ${ }^{(9-11)}$, due to fear or apprehension of getting infected ${ }^{(16)}$. In the same context, people also avoid seeking medical help in case of common symptoms of cold or flu (which has overlapping symptoms of COVID-19) fearing screening and a positive COVID-19 diagnosis results in social exclusion, unwanted public attention and the stigma attached with the disease.

Age and occupation have similar prevalence rate of severity of general anxiety,whereas, a different prevalence rate of severity of symptoms of depression (Table 1 and 2). Younger participants showed higher prevalence of moderate to severe anxiety (statistically not significant) and depression symptoms when compared to the participants aged more than or equal to 30 years. Huang et al. and Rossi et al. also found similar results ${ }^{(10,11)}$. However, Wang et al. analyzed various different age groups ranging from 12 to 60 years and found no difference between these groups ${ }^{(9)}$. Increased depressive symptoms might be due to social isolation, limitation of outdoor activities and avoidance behaviour to limit socialization. Younger population tends to be moresocially-interactive than the middle-age population $^{(17)}$, therefore, it might be stressful for them to sit at home during the lockdown. Also, poor coping strategies or immature defence mechanism among the younger population combined with the stressful situation may lead to maladaptive behaviour ${ }^{(18)}$.

Our study also found that students are more prone to mild anxiety and moderate depression. Wang et al. also found the association of students with presence of anxiety and depression during the COVID-19 pandemic ${ }^{(9)}$.
Increase in depression is due to uneasiness experienced of risk exposure to the virus and thoughts about family and friends contracting the virus or suspected of being infected by the virus ${ }^{(19)}$.Our study recruited mostly under-graduate or post-graduate students from different universities. We believe that sudden implementation of virtual online classes at universities can resultin a negative mental effect due to unfamiliarity with online teaching methodologies. Uncertainty regarding duration of quarantine, frustration and boredom due to disruption of usual routine, loss of social networks and confinement within the four walls leads to a sense of isolation ${ }^{(20)}$ which further leads to deteriorating mental health.

Our study also found that the severity of anxiety and depression symptoms depended upon the time spent on gathering information regarding COVID-19. We found that participants who spent $>3$ hours on COVID-19 information were strongly associated with mild, moderate or severe anxiety as well as depression. Roy et al. reported that the stress related to COVID-19 in India is mostly due to seeing COVID-19 related posts on social media, discussion on news channels and print mediaand rampant spread of rumors via social media platforms ${ }^{(12)}$. They reported that the participants want to talk about the anxieties and stress related to COVID-19 with someone, but have to rely on electronic, social media and internet information which reduces the opportunities to de-stress. Also, media reporting about the shortage of resources and essential things for daily living further increasedpanic buying. As a result, people are not able to cope with the situation and feel emotionally exhausted.

Therefore few recommendations from this study are listed herein: First, limit the time spent on COVID-19 information to maximum one hour per day since excessive exposure to information. Second, minimize watching, reading or listening to news about COVID-19 and seeking information about the pandemic once or twice a day and it was further recommended that people should seek information only from trusted sources to get the true facts instead of rumors or misinformation ${ }^{(21)}$. Third, control over rumors, clear overview of authorities on the pandemic, health education and spread of knowledge of preventive measures could be implemented to reduce the negative mental impact of the pandemic.

This study had several limitations. The sample size is small which may limit the power of results. Snowball samplingtechniques resulted in self-selection biasness due to which an unbalanced occupation ratio 
was seen. A major percentage (58\%) of respondents were students. The study was conducted during the outbreak of COVID-19 in India, so participants' prior history of psychological state was not known and moreover, the anxiety and depression revealed in the study is selfreported and may not always clinically align with the diagnosis by mental health professionals. Future studies should be conductedduring different phases of lockdown including rural population. Further studies are required to monitor the impact of mental health outcomes in order to define mental health interventions for the general population level.

\section{Conclusions}

Participants with $<30$ years of age were found to be associated with mild, moderate and severe depression. Students were more likely to have mild anxiety and moderate depressive symptoms. Participants who were spending more than three hours on gatheringinformationon COVID-19 were strongly associated with mild, moderate and severe anxiety as well as depression.

\section{Conflict of Interest: None}

Source of Funding: Authors are self-contributor as a source of funding. Present study was not funded by any organization or agency.

Ethical Clearance: Expedited ethical approval was taken from the local ethical board, Galgotias University, Noida, Uttar Pradesh.

\section{References}

1. Worldometer. Coronavirus Cases. Worldometer [Internet]. 2020 [cited 2020 Apr 29];164:1-22.

2. Statista. Coronavirus (COVID-19) in India Statistics \& Facts. 2020. https://www.statista.com/ topics/6135/coronavirus-covid-19-outbreak-inindia/

3. Dong L, Bouey J. Public Mental Health Crisis during COVID-19 Pandemic, China. Emerg Infect Dis. 2020;26(7).

4. Liu R, Wu J, Zhu H. Media/psychological impact on multiple outbreaks of emerging infectious diseases. Comput Math Method Med. 2007;8(3):153-64.

5. Strong P. Epidemic psychology: a model. Sociol Heal Illn. 1990;12(3):249-59.

6. Person B, Sy F, Holton K, Govert B, Liang A,
NCID/SARS T, et al. Fear and Stigma: The Epidemic within the SARS Outbreak. Emerg Infect Dis. 2004;10(2):358.

7. DiGiovanni C, Conley J, Chiu D, Zaborski J. Factors Influencing Compliance with Quarantine in Toronto During the 2003 SARS Outbreak. Biosecurity Bioterrorism Biodefense Strateg Pract Sci. 2004;2(4):265-72.

8. Hawryluck L, Gold WL, Robinson S, Pogorski S, Galea S, Styra R. SARS control and psychological effects of quarantine, Toronto, Canada. Emerg Infect Dis. 2004;10(7):1206-12.

9. Wang C, Pan R, Wan X, Tan Y, Xu L, Ho CS, et al. Immediate psychological responses and associated factors during the initial stage of the 2019 coronavirus disease (COVID-19) epidemic among the general population in China. Int J Environ Res Public Health. 2020;17(5).

10. Huang Y, Zhao N. Generalized anxiety disorder, depressive symptoms and sleep quality during COVID-19 epidemic in China: a web-based crosssectional survey 2 3. Psychiatry Res. 2020;112954.

11. Rossi R, Socci V, Talevi D, Mensi S, Niolu C, Di Marco A, et al. COVID-19 pandemic and lockdown measures impact on mental health among the general population in Italy. An N=18147 webbased survey. medRxiv. 2020.

12. Roy D, Tripathy S, Kumar Kar S, Sharma N, Kumar Verma S, Kaushal V. Study of knowledge, attitude, anxiety \& perceived mental healthcare need in Indian population during COVID-19 pandemic. Asian J Psychiatr. 2020;51:102083.

13. Spitzer RL, Kroenke K, Williams JB. Generalized anxiety disorder 7-item (GAD-7) scale. Arch Intern Med. 2006;166:1092-7.

14. Martin A, Rief W, Klaiberg A, Braehler E. Validity of the Brief Patient Health Questionnaire Mood Scale (PHQ-9) in the general population. Gen Hosp Psychiatry. 2006;28(1):71-7.

15. Liu N, Zhang F, Wei C, Jia Y, Shang Z, Sun L, et al. Prevalence and predictors of PTSS during COVID-19 Outbreak in China Hardest-hit Areas: Gender differences matter. Psychiatry Res. 2020;112921.

16. Su T-P, Lien T-C, Yang C-Y, Su L, Wang J-H, Tsai S-L, et al. Prevalence of psychiatric morbidity and psychological adaptation of the nurses in a structured SARS caring unit during outbreak: 
A prospective and periodic assessment study in Taiwan q. J Psychiatr Res. 2007;41(1-2):119-30.

17. Ybarra O, Burnstein E, Winkielman P, Keller MC, Manis M, Chan E, et al. Mental Exercising Through Simple Socializing: Social Interaction Promotes General Cognitive functioning. 2008;34(2):248-59.

18. Whitty MT. Coping and defending: Age differences in maturity of defence mechanisms and coping strategies. Aging Ment Health. 2003;7(2):123-32.
19. Liu X, Liu J, Zhong X. Psychological State of College Students During COVID-19 Epidemic. Lancet. 2020;SSRN 3552814.

20. Blendon RJ, Benson JM, DesRoches CM, Raleigh E, Taylor-Clark K. The public's response to severe acute respiratory syndrome in Toronto and the United States. Clin Infect Dis. 2004;38(7):925-31.

21. Mental health and psychosocial considerations during the COVID-19 outbreak, 18 March 2020. World Health Organization; 2020. 